\title{
Expert panel's modification and concurrent validity of the Teacher Stress Inventory among selected secondary school teachers in Nigeria
}

\author{
Victor O. Lasebikan
}

\begin{abstract}
Background: The Teacher Stress Inventory (TSI) is an instrument used for assessing occupational stress among teachers but has not been adapted or validated for use in Nigeria.

Objective: This study aimed to modify and adapt the TSI for use in Nigeria and also assess its reliability and validity. An expert panel was constituted to modify the original version of the TSI. Thereafter, both the original and the modified versions were applied to 471 teachers from 15 schools in Oyo State, Nigeria.

Result: Of all the respondents, 227 (48.2\%) were men and 244 (51.8\%) were women. Mean age was $36.55 \pm 8$. 80 years. Cronbach a for all items of the modified version was .943, and item mean score was 2.60 (1.86-3.56). Concurrent validity of the modified TSI demonstrated significant correlations $p<0.001$ with the corresponding items of the original version. Test-retest reliability of the modified version was .988. There were significant inter-item correlations for all the items of the modified version of the TSI.
\end{abstract}

Conclusion: The modified version of the TSI is a valid and reliable instrument in the Nigerian population to assess teachers' stress.

Keywords: Teacher Stress Inventory, Validity, Reliability, Teachers, Nigeria

\section{Background}

The impact of the teaching profession on the psychological health of teachers is of utmost public health importance all over the world (Abel and Sewell 1999; Baldacara et al. 2015; Chan 2000; Johnson et al. 2005), and the construct of "teachers' stress" which has been conceptualized as having both emotional and physical substrates resulting from some aspect of their work (Freudenberger 1974) is well recognized. Despite this, teachers' stress is largely determined by varying contextual perception and sociocultural factors (Bhagat et al. 2007).

In the developed countries of the world, assessing teachers' stress with valid instruments has been found to be significantly helpful in order to improve their health and to build policy decisions regarding health care

Correspondence: victorlash@yahoo.com

Department of Psychiatry, College of Medicine, University of Ibadan, PMB 5116, Ibadan, Nigeria

services. This led to the development of a teacherspecific valid instrument for the assessment of teachers' work-related stress (Fimian 1984).

Before the development of the Teacher Stress Inventory (TSI), the phenomenon of teachers' stress was difficult to access as it was equated with burnout. Therefore, the psychometric constructs of teachers' stress were devised with the understanding that burnout is the product of longstanding stress (Fimian and Fastenau 1990). Thus, in an attempt to specifically assess "different stress experiences" that are particular to the teaching profession, the TSI was developed (Fimian 1984). However, such instrument should be culturally and contextually applicable in Nigeria, requiring its modification and comparison with the original version in order to achieve this. The original version of the TSI is a psychometrically valid and reliable self-administered instrument used in the measurement of teacher stress developed by Fimian in 1984 for the 
assessment of occupational stress in teachers (Fimian 1984). The TSI has been widely used in North America, where it was developed and also in Africa (Atindanbila 2011; Paulse 2005). This 49-item instrument assesses issues relating to time management, work-related stressors, discipline and motivation, professional investment, emotional manifestations, fatigue manifestations, cardiovascular manifestations, gastronomical manifestations, and behavioral manifestations. The original version of the TSI has ten factors, of which the item content was based on the experiences of public school teachers working in both regular and special education schools. When the psychometric property of the TSI was determined in South Africa, items 1 (I easily over-commit myself), 3 (I have to try doing more than one thing at a time), and 6 (I feel uncomfortable wasting time) were omitted (Boshoff 2011).

In the Nigerian context, given differences in ethnicity, religion, demographics, political, organizational, and social support systems compared to the Western world, where the TSI was developed and adapted for use, sources and reaction to stress are expected to differ significantly. Even within Nigeria, there is a wide cultural variation of a stressor that will be significant enough to constitute a stress reaction (Sheikh et al. 2014). Thus, instruments that will be applicable to assess teachers' stress in Nigeria must consider these contextual factors. Specifically, among teachers in Nigeria, lack of resources for teaching, dilapidated teaching infrastructures (Okebukola and Jegede 1989), organizational problems such as high student-pupil ratio, high work load (Akpochafo 2012), delay in wage payment spanning almost a year in some instances, delay or absence of promotion, and lack of teaching materials (Duyilemi 1992) are some of the factors that have been identified as being stressful in their industry. From previous studies in Nigeria, an identified gap is the lack of standardized and valid instruments in the assessment of teachers' stress (Adeoye and Okonkwo 2010; Olaitan et al. 2010).

Thus, our main aim was to modify the original version of the TSI within the Nigerian context using an expert panel on the subject matter and to also pilot test the modified version among selected secondary school teachers. In the current study, the original and the modified versions of the TSI were compared for correlation.

\section{Methods}

\section{Participants}

The sample size was statistically estimated using sample size formula for descriptive studies as follows: $n=Z^{2} p q / d^{2}$ (Kish 1965).

$n=$ desired sample size

$z=\mathrm{SD}$ at $1.96 \equiv 95 \%$ of confidence interval

$p=$ prevalence rate of desired characteristic in the target population $(0.459)$

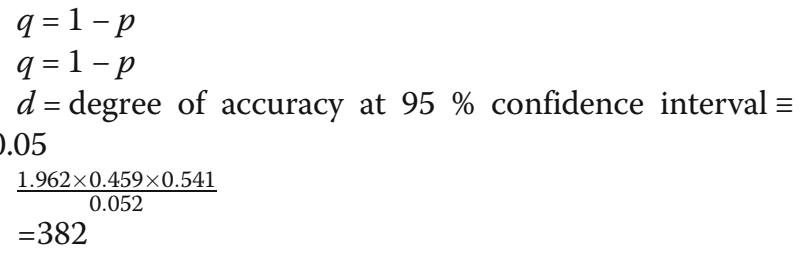

The minimum sample size $=382$

Due to the possibility of nonresponse and to increase precision, the new sample size was calculated as follows:

$\mathrm{Ns}=n / \mathrm{ar}$

$\mathrm{Ns}=$ selected sample size

$n=$ calculated sample size

ar $=$ anticipated response rate $(80 \%)$

This yielded 477 . However, 471 completed the study.

In this descriptive study, a multistage sampling method was used in selecting 471 teachers from 52 private and 86 government secondary schools in the Ibadan North Local Government Area, Oyo State, Nigeria. These participants $(n=471)$ were selected through a multistage sampling technique from 138 secondary schools in the Ibadan North Local Government Area. In the final stage of sample selection, the number of teachers that were interviewed was determined by a proportional sampling method. The first teacher was randomly selected, and others were consecutively interviewed until the sample size in that school was met.

The selected teachers were allocated tallies on which the serial number on their questionnaire was written. The serial number provided a means of maintaining confidentiality and accountability throughout the study period.

\section{Instruments}

\section{Sociodemographic teacher-specific questionnaire}

This is a pre-tested, pre-coded questionnaire developed by the researchers to collect information about the respondents' sociodemographic characteristics such as age, length of job experience, marital status, number of children, salary, and other job characteristics.

\section{The Teacher Stress Inventory}

This is a psychometrically valid and reliable selfadministered instrument used in the measurement of teacher stress developed by Fimian in 1984 for the assessment of occupational stress in teachers (Fimian 1984).This 49-item instrument assesses issues relating to time management, work-related stressors, discipline and motivation, professional investment, emotional manifestations, fatigue manifestations, cardiovascular manifestations, gastronomical manifestations, and behavioral manifestations.

The TSI proposed a means of measuring the complex entity of occupational teacher stress. TSI is applicable 
within the school-, system-, or a more generalized statewide survey of teacher stress. The administration time of the TSI is about $15 \mathrm{~min}$.

Scoring: TSI is a self-rating scale that is rated from a 1 to 5 Likert-like manner from no strength, mild strength, medium strength, great strength, to major strength. A mean score is thereafter obtained for each item.

\section{Modification procedure}

The modification process was carried out in two phases by an expert panel comprising of psychiatrists, senior psychiatric nurses, clinical psychologists, senior teachers, and social workers with at least 3 years of professional experience. This was to access its acceptability, practicality, and face validity. The expert panel evaluated the content validity of the original TSI. The composition of the expert panel included the three major ethnic groups in Nigeria (Hausa/Fulani, Igbo, and Yoruba). In all, six items were modified. The final modified and deleted items are presented in Table 1.

In original item 8, "I rush in my speech" was modified to "I rush in my speech or find it difficult to communicate fluently in English when under pressure" because not all teachers are fluent in English.

In original item 14, "There is too much administrative paperwork in my job" was deleted and replaced with "The school system has structural and functional problems." This is because original item 10 "there is too much work to do" incorporates original question 14 "There is too much administrative paperwork in my job."

In original item 16, "I am not progressing on my job as rapidly as I would like" was deleted and replaced with "I have frequent teacher-teacher or teacher- superior authority conflict e.g. with the ministry or board of directors." This is because original item 16 seems a duplication of original item 15 "I lack promotion and/ or advancement opportunities."

Original item 18 "I receive an inadequate salary for the work I do" was modified to "I receive an inadequate or late wages for the work I do." This is because late payment of salary is very frequent within this population of workers.

Original item 46 "I respond to stress by using over-the counter drugs" was merged with original item 47 "I respond to stress by using prescription drugs." New item 46 becomes "I respond to stress by using over-the counter drugs or prescription medication." This is because several over-the-counter drugs are prescription medication within this study population area.

In original item 47, "I respond to stress by using prescription drugs" was modified to "I respond to stress by taking alcohol or illegal drug." This is because of the use of illegal drugs such as cannabis or alcohol in time of stress.

Pilot study Following the modification process, a pilot study was carried out among 50 teachers selected from two secondary schools (32 from a public school and 18 from a private school) before the main study. The schools selected had similar organizational characteristics to the population proposed for this study. During the pilot study, an in-depth interview was conducted to source for issues of concern for the teachers. The findings were thereafter used in constructing questions added to the source-demographic questionnaire that was used for the study. The pilot study enabled the researcher to assess the feasibility of the study and the adequacy of the entire research protocol.

Table 1 Modifications of the original TSI made by the final expert panel

\begin{tabular}{|c|c|c|c|c|}
\hline $\begin{array}{l}\text { Question } \\
\text { number }\end{array}$ & Original questions & Modified/deleted/added questions & Action & Reason \\
\hline 8 & I rush in my speech. & $\begin{array}{l}\text { I rush in my speech or find it difficult to } \\
\text { communicate fluently in English when } \\
\text { under pressure }\end{array}$ & $\begin{array}{l}\text { Original question } \\
8 \text { modified }\end{array}$ & Not all teachers are fluent in English \\
\hline 14 & $\begin{array}{l}\text { There is too much } \\
\text { administrative paperwork } \\
\text { in my job }\end{array}$ & $\begin{array}{l}\text { The school system has structural and } \\
\text { functional problems }\end{array}$ & $\begin{array}{l}\text { Original question } 14 \\
\text { deleted, new question } \\
14 \text { added }\end{array}$ & $\begin{array}{l}\text { Original question } 10 \text { should } \\
\text { incorporate original question } 14\end{array}$ \\
\hline 16 & $\begin{array}{l}\text { I am not progressing on } \\
\text { my job as rapidly as } \\
\text { I would like. }\end{array}$ & $\begin{array}{l}\text { I have frequent teacher-teacher or } \\
\text { teacher- superior authority conflict e.g } \\
\text { with the ministry or board of directors }\end{array}$ & $\begin{array}{l}\text { Original question } \\
16 \text { deleted, new question } \\
16 \text { added }\end{array}$ & $\begin{array}{l}\text { Original question } 16 \text { seems a } \\
\text { duplication of original question } 15\end{array}$ \\
\hline 18 & $\begin{array}{l}\text { I receive an inadequate } \\
\text { salary for the work I do }\end{array}$ & $\begin{array}{l}\text { I receive an inadequate or late wages } \\
\text { for the work I do }\end{array}$ & $\begin{array}{l}\text { Original question } \\
18 \text { modified }\end{array}$ & $\begin{array}{l}\text { Late payment of salary is very } \\
\text { frequent within this population }\end{array}$ \\
\hline 46 & $\begin{array}{l}\text { I respond to stress by using } \\
\text { over-the counter drugs }\end{array}$ & $\begin{array}{l}\text { I respond to stress by using over-the } \\
\text { counter drugs or prescription medication }\end{array}$ & $\begin{array}{l}\text { Original questions } \\
46 \text { and } 47 \text { merged }\end{array}$ & $\begin{array}{l}\text { This is because several over-the } \\
\text { counter drugs are prescription } \\
\text { medication within this population }\end{array}$ \\
\hline 47 & $\begin{array}{l}\text { I respond to stress by } \\
\text { using prescription drugs }\end{array}$ & I respond to stress by using illegal drug & $\begin{array}{l}\text { Original questions } \\
47 \text { modified }\end{array}$ & $\begin{array}{l}\text { This is because of use of illegal drugs } \\
\text { such as cannabis in time of stress }\end{array}$ \\
\hline
\end{tabular}


Thereafter, the original 49-item version of the TSI and the modified version of the TSI were administered to the 471 teachers.

All the participants were used for validity and reliability assessments, but only half (236) was used for the test-retest reliability of the modified version. The retest was carried out at 2 weeks after the initial assessment.

\section{Statistical analysis}

Sociodemographic data are presented as frequency tables. The internal consistency of the modified version was determined from the Cronbach's alpha coefficient, with values of 0.7 and above considered as acceptable. Concurrent validity of the modified version of the TSI was determined by determining the correlation of its mean scores with the original version using Pearson correlation analysis. Inter-item correlation of the modified version of the TSI was also determined using Pearson's correlation analysis. The independent $t$ test and the ANOVA were used to compare the mean TSI scores according to sociodemographic characteristics. Post hoc pairwise comparisons were carried out after the ANOVA using Tukey test. All analyses were set at $p<0.05,95 \%$ CI. Statistical Package for the Social Sciences version 20.0 was used for data analyses.

\section{Results}

Results of modification

During the validation process, questions $8,18,46$, and 47 were modified; questions 14 and 16 were deleted and replaced with new ones (Table 1).

\section{Demographics}

The sample consisted of 477 teachers, out of which 471 fully participated, indicating a response rate of $98.7 \%$. Their mean age was $36.38 \pm 8.87$ years. The characteristics of the sample are shown in Table 2. About two thirds of the participants, $65.6 \%$, worked in the public sector, $48.2 \%$ were men, $63.5 \%$ were ever married, and only $7.8 \%$ were over 49 years of age. The vast majority, $82.0 \%$, was teaching either senior or junior classes.

\section{Teachers' stress}

Participants who were married recorded higher mean modified TSI scores compared with those who were not married, $t=2.04, p=.03$; private sector teachers reported higher mean modified TSI scores compared with their public sector counterparts, $t=3.3, p=.001$, while those who were teaching a combination of senior and junior classes also recorded a higher mean modified TSI score compared with those teaching either class, $t=2.32$,

Table 2 Sociodemographic characteristics of participants

\begin{tabular}{|c|c|c|c|c|c|}
\hline Variables & Number & Percent & Mean (SD) & Statistics & $p$ \\
\hline \multicolumn{6}{|l|}{ Age group } \\
\hline $20-29$ & 118 & 25.1 & $2.50(0.72)$ & \multirow[t]{4}{*}{$2.03 \mathrm{~F}$} & \multirow[t]{4}{*}{0.11} \\
\hline $30-39$ & 138 & 29.3 & $2.71(0.80)$ & & \\
\hline $40-49$ & 178 & 37.8 & $2.59(0.74)$ & & \\
\hline $50-59$ & 37 & 7.8 & $2.68(0.76)$ & & \\
\hline \multicolumn{6}{|l|}{ Gender } \\
\hline Male & 227 & 48.2 & $2.67(0.72)$ & \multirow[t]{2}{*}{$1.76 \mathrm{t}$} & \multirow[t]{2}{*}{0.08} \\
\hline Female & 244 & 51.8 & $2.55(0.79)$ & & \\
\hline \multicolumn{6}{|l|}{ Marital status } \\
\hline Ever married & 299 & 63.5 & $2.65(0.82)$ & \multirow[t]{2}{*}{$2.04 \mathrm{t}$} & \multirow[t]{2}{*}{0.03} \\
\hline Never married & 172 & 36.5 & $2.51(0.64)$ & & \\
\hline \multicolumn{6}{|l|}{ Type of school } \\
\hline Public sector & 309 & 65.6 & $2.51(0.68)$ & \multirow[t]{2}{*}{$-3.30 t$} & \multirow[t]{2}{*}{0.001} \\
\hline Private sector & 162 & 34.4 & $2.77(0.87)$ & & \\
\hline \multicolumn{6}{|l|}{ Class grade taught } \\
\hline Senior or junior only & 386 & 82.0 & $2.46(0.62)$ & \multirow[t]{2}{*}{$-2.32 t$} & \multirow[t]{2}{*}{0.02} \\
\hline Senior and junior combined & 85 & 18.0 & $2.64(0.78)$ & & \\
\hline \multicolumn{6}{|l|}{ Subjects taught } \\
\hline Arts & 183 & 38.9 & $2.47(0.53)$ & \multirow[t]{3}{*}{$27.7 F$} & \multirow[t]{3}{*}{$<0.001$} \\
\hline Science & 213 & 45.2 & $2.77(0.78)$ & & \\
\hline Commercial & 75 & 15.9 & $2.18(0.59)$ & & \\
\hline
\end{tabular}

$t$ independent $t$ test, $F$ ANOVA 
$p=.02$. There was also a significant difference in the mean modified TSI score based on subjects taught, $F=27.7$, $p<.001$. Post hoc test showed that this was accounted for by a higher mean modified TSI score for teachers teaching science subjects compared with those teaching either arts or commercial subjects, $p<.001$, respectively, and also by a higher mean modified TSI score for those teaching arts subjects compared with those teaching commercial subjects, $p<.001$ (Table 2).

Cronbach $\alpha$ for all the items of the original version was .942 and for the modified version was .943 . Item mean score was $2.60(1.86-3.56)$. Test-retest reliability of the modified version was .988 . For the five subscales of the stress factors, the original and modified TSI factor mean scores and their corresponding concurrent validity yielded significant correlations $p<.001$, respectively. Also, the original and modified TSI factor mean scores and their corresponding concurrent validity yielded significant correlations $p<.001$ for all the five subscales of the manifestation of stress, $p<.001$, respectively (Table 3 ). Despite these significant correlations, there were significant differences in the mean scores between the modified version of the TSI and the original version in the areas of time management $p=.004$, work-related stressors $p<.001$, professional investment $p<.001$, emotional manifestations $p<.001$, fatigue manifestations $p<.001$, cardiovascular manifestations $p=.003$, behavioral manifestations $p<.001$, and total TSI $p<.001$.

There were significant inter-item correlations for all the items of the modified version of the TSI, $p<.001$ for each item pair (Table 4).

\section{Discussion}

This study is an important contribution in the assessment of Nigerian teachers' stress. It is also a major contribution to the modification and validity of an instrument that is applicable to a specific population. This study supports the reliability and validity of the Nigerian version of the TSI. The results show that construct validity, internal consistency, and concurrent validity of the modified version of TSI along with its corresponding subscales were generally supported by this representative sample of Nigerian teachers. Findings from the present report support that stress sources and stress manifestations are the two factors of the TSI. The internal reliability analysis of the TSI and its ten subscales showed satisfactory alpha coefficients, within the range of other studies (Kourmousi et al. 2015) and the original version of the TSI (Fimian 1984). It was previously noted that a modest Cronbach's coefficient of 0.7 could be regarded desirable during scale validation (Nunnally and Bernstein 1994). Figures that were above 0.7 were reported in all the ten factors of the modified version. Also, all the ten factors of the modified version of the TSI showed significant correlations. This was achieved by a rigorous and meticulous process of adaptation of the instrument during the pilot study.

The concurrent validity analysis indicated that the modified TSI was extremely correlated with the original version and all the correlation coefficient of the factors were 0.95 and above. Beyond these, higher TSI scores were generally reported for the stress sources rather than stress manifestations. This is consistent with findings from other studies which showed stress sources to be most frequently reported compared to stress manifestations (Kourmousi et al. 2015), probably because sources of stress may be easier to identify than its common manifestations. Also consistent with previous studies was the observation that emotional (Olivier and Venter 2003) and fatigue manifestations (Tsai et al. 2006) were the most common stress manifestations reported in the present study.

Table 3 Concurrent validity of the items of the original TSI and the modified TSI

\begin{tabular}{|c|c|c|c|c|c|c|c|c|}
\hline & Number of Items & $\begin{array}{l}\text { Original TSI } \\
\text { Mean (SD) }\end{array}$ & $\begin{array}{l}\text { Modified TSI } \\
\text { Mean (SD) }\end{array}$ & $R$ & $p$ & $\begin{array}{l}\text { Modified TSI } \\
\text { Cronbach a }\end{array}$ & $t$ & $p$ \\
\hline \multicolumn{9}{|l|}{ Stress factors } \\
\hline Time management & 8 & $2.87(0.84)$ & $2.86(0.83)$ & 0.99 & $<0.001$ & 0.78 & 2.88 & 0.004 \\
\hline Work-related stressors & 6 & $2.69(0.97)$ & $2.68(0.96)$ & 0.99 & $<0.001$ & 0.79 & 2.69 & $<0.001$ \\
\hline Professional distress & 5 & $3.19(1.04)$ & $3.19(1.04)$ & 1.0 & $<0.001$ & 0.77 & - & - \\
\hline Discipline and motivation & 6 & $2.70(1.03)$ & $2.69(0.97)$ & 0.98 & $<0.001$ & 0.80 & 0.36 & 0.7 \\
\hline Professional investment & 4 & $2.59(1.09)$ & $2.58(1.04)$ & 1.0 & $<0.001$ & 0.76 & 3.25 & 0.001 \\
\hline \multicolumn{9}{|l|}{ Manifestation of stress } \\
\hline Emotional manifestations & 5 & $2.39(1.08)$ & $2.44(1.03)$ & 0.95 & $<0.001$ & 0.79 & -3.67 & $<0.001$ \\
\hline Fatigue manifestations & 5 & $2.65(1.02)$ & $2.63(1.01)$ & 0.98 & $<0.001$ & 0.78 & 4.93 & $<0.001$ \\
\hline Cardiovascular manifestations & 3 & $2.29(1.18)$ & $2.28(1.17)$ & 0.99 & $<0.001$ & 0.79 & 3.02 & 0.003 \\
\hline Gastronomical manifestations & 3 & $1.94(1.12)$ & $1.94(1.13)$ & 1.0 & $<0.001$ & 0.82 & - & - \\
\hline Behavioral manifestations & 4 & $2.03(1.03)$ & $1.97(1.04)$ & 0.98 & $<0.001$ & 0.88 & 34.65 & $<0.001$ \\
\hline Total & 49 & $2.64(0.78)$ & $2.61(0.96)$ & 0.99 & $<0.001$ & 0.94 & 4.52 & $<0.001$ \\
\hline
\end{tabular}


Table 4 Correlations between the modified Teacher Stress Inventory scales

\begin{tabular}{lllllllllll}
\hline & & TM & WRS & PD & DM & PI & EM & FA & CARD & GAST \\
\hline WRS & $R$ & .58 & & & & & & & & \\
PD & $R$ & .35 & .42 & & & & & & & \\
DM & $R$ & .44 & .48 & .40 & & & & & & \\
PI & $R$ & .42 & .32 & .40 & .58 & & & & & \\
EM & $R$ & .43 & .48 & .37 & .65 & .58 & & & & \\
FA & $R$ & .30 & .35 & .25 & .41 & .47 & .63 & & & \\
CARD & $R$ & .27 & .20 & .18 & .36 & .54 & .43 & .47 & & \\
GAST & $R$ & .34 & .34 & .18 & .38 & .44 & .41 & .48 & .57 & \\
BE & $R$ & .35 & .37 & .24 & .41 & .41 & .46 & .39 & .58 & .63 \\
\hline
\end{tabular}

Note: All correlations were significant at the $<0.001$ level Abbreviations: $B E$ behavioral manifestations, $C A R D$ cardiovascular manifestations, $D M$ discipline and motivation, $E M$ emotional manifestations, $F A$ fatigue manifestations, GAST gastronomic manifestations, PD professional distress, $P I$ professional investment, TM time management, WRS work-related stressors

It this study, respondents who were married were found to have higher stress level, which could be adduced to additional responsibility of being married. An interesting finding is the differential level of stress between public and private sector teachers, with teachers in the public sector having a lower level of stress despite the highly deplorable structural and functional factors that are potential sources of stress for these teachers, which may be suggestive of cognitive dissonance (Festinger 1957) among them.

The observed high level of stress among teachers of science subjects, followed by those teaching arts subjects, and also among those teaching combined senior and junior classes has corroborated documented reports that it is often easy to identify sources of stresses among teachers (Kourmousi et al. 2015).

All of the abovementioned findings support the evidence that the modified version of the TSI can discriminate groups with high stress levels in this sample of Nigerian teachers' population.

In the present study, standardized procedures, including modification, deletion, and inclusion of some questions, were adopted. Using focus group discussion and the use of an expert panel, the face and the content validity of the modified TSI were established. The findings from the pilot test conducted before the present study revealed that the TSI wordings of the instrument were well understood by the teachers and the instrument had acceptable administration time.

The expert panel members agree on the following issues: question 8 which states "I rush in my speech" was modified to "I rush in my speech or find it difficult to communicate fluently in English when under pressure" because not all teachers are fluent in English when under pressure, making some teachers converse in the native language under such circumstances. Question 14 which states "there is too much administrative paperwork in my job" was deleted because it may be included in question 10. Question 14 was then substituted with "the school has structural and functional problems." This is because a number of issues create stress for teachers in the state where the study was carried out. Many schools are dilapidated, and students on some occasions bring their own tables and chairs to school everyday. Question 16 which states "I am not progressing on my job as rapidly as I would like" was deleted as it duplicates question 15. It is replaced by "I have frequent teacher-teacher or teachersuperior authority conflict, for example, with the ministry or board of directors." This took into consideration interpersonal and organizational factors that lead to stress. Question 18 which states "I receive an inadequate salary for the work I do" was modified to "I receive an inadequate or late wages for the work I do." This is because late payment of salary is very frequent and constitutes significant stress to the teachers in this environment. Question 46 which states "I respond to stress by using over-the counter drugs" was modified to "I respond to stress by using over-the counter drugs or prescription medication." This is because several over-the-counter drugs are prescription medication within this population. Question 47 which reads "I respond to stress by using prescription drugs" was modified to "I respond to stress by using illegal drug." This was to incorporate the use of illegal drugs such as cannabis in time of stress.

In the current study, the original TSI was validated in order to identify and resolve the peculiar stress-related problems of Nigerian teachers. This is believed to be a crucial step in the production of context-dependent instrument that will determine or actually define what constitutes teachers' stress.

The strength of this study lies in the rigorous way of validating the TSI. Although there are cultural variation in beliefs and practice in Nigeria, the inclusion of the major ethnic group during the validation process is highly invaluable.

This study has certain limitations. It has not carried out a factor analysis of the modified version. This will be addressed in future reports.

Also, the absence of a clinically diagnosable group with DSM-IV or ICD-10 stress pathology makes comparison difficult in order for the modified version of the TSI to show evidence of its discriminative ability.

\section{Conclusions}

In conclusion, the present study provides evidence that the modified TSI is a reliable and valid instrument for measuring stress in Nigerian teachers. It has yielded information for some demographic and related factors of stress. 


\section{Acknowledgements}

Acknowledgement is given to the Director of Planning, Research and Statistics, Oyo State Ministry of Health, Ibadan, for granting ethical approval for this study. Acknowledgement with thanks is also given to Dr. FT Asa (MB BS, FWACP), who assisted in collecting permission for the study from the original author of the instrument.

\section{Funding}

No specific funding.

\section{Competing interests}

The author declares that he has no competing interests.

\section{Ethics approval and consent to participate}

Participants provided written informed consent. Ethical approval was obtained from the Ethical Review Committee, Department of Research, Planning and Statistics, Ministry of Health, Oyo State, Nigeria. Permission for the study was also obtained from the Ministry of Education.

A copyright permission was sought from Michael Fimian via his email address Fimian@InstructionalTech.net. This requirement is stipulated on the website for prospective researchers (www.instructionaltech.net/TSI/). Efforts were made to ensure that the study was conducted during the break time and shortly after the school period. This was to avoid any disruption in the routine activities of the participants.

\section{Received: 10 February 2016 Accepted: 6 September 2016}

Published online: 18 September 2016

\section{References}

Abel, M. H., \& Sewell, J. (1999). Stress and burnout in rural and urban secondary school teachers. The Journal of Educational Research, 92(5), 287-293. doi:10.1080/00220679909597608.

Adeoye, O. A., \& Okonkwo, N. E. (2010). Gender and school types as factors responsible for job stress in Nigeria universities. Edo Journal of Counselling, $3(2), 1-9$.

Akpochafo, G. O. (2012). Self-efficacy and some demographic variables as predictors of occupational stress among primary school teachers in delta state of Nigeria. International Journal of Arts and combined Sciences, 3(1), 1-8.

Atindanbila, S. (2011). Perceived stressors of lecturers at the University of Ghana. Journal of Emerging Trends in Educational Research and Policy Studies (JETERAPS), 2(5), 347-354.

Baldacara, L., Silva, A. F., Castro, J. G., \& Santos, G. C. (2015). Common psychiatric symptoms among public school teachers in Palmas, Tocantins, Brazil. An observational cross-sectional study. São Paulo Medical Journal, 133(5), 435-438. doi:10.1590/1516-3180.2014.8242810.

Bhagat, R. S., Steverson, P. K., \& Segovis, J. C. (2007). International and cultural variations in employee assistance programmes: implications for managerial health and effectiveness. Journal of Management Studies, 44(2), 222-242.

Boshoff, S. M. (2011). Validation of the Teacher Stress Inventory (TSI) in a South African context : the SABPA study from. http://hdl.handle.net/10394/6277. Accessed 4 Jan 2016.

Chan, D. (2000). Dimensionality of hardiness and its role in the stress-distress relationship among Chinese adolescents in Hong Kong. Journal of Youth and Adolescence, 29(2), 147-161. doi:10.1023/A:1005100531194.

Duyilemi, B. O. (1992). Source and social correlates of occupational stress among Nigerian primary school teacher. Nigerian Journal of Educational Foundations, $3(1), 35-46$

Festinger, L. (1957). A theory of cognitive dissonance. Stanford: Stanford University Press.

Fimian, M. J. (1984). The development of an instrument to measure occupational stress in teachers: the Teacher Stress Inventory. Journal of Occupational Psychology, 57(4), 277-293.

Fimian, M. J., \& Fastenau, P. S. (1990). The validity and reliability of the Teacher Stress Inventory: a re-analysis of aggregate data. Journal of Organizational Behaviour, 11(2), 151-157. doi:10.1002/job.4030110206.

Freudenberger, H. J. (1974). Staff burnout. Journal of Social Issues, 30(1), 159-165.

Johnson, S., Cooper, C., Cartwright, S., Donald, I., Taylor, P., \& Millet, C. (2005). The experience of work-related stress across occupations. Journal of Managerial Psychology, 20(2), 178-187.

Kish, L. (1965). Survey sampling. New York: John Wiley.
Kourmousi, N., Darviri, C., Varvogli, L., \& Alexopoulos, E. C. (2015). Teacher Stress Inventory: validation of the Greek version and perceived stress levels among 3,447 educators. Psychology Research and Behaviour Management, 8, 81-88. doi:10.2147/PRBM.S74752

Nunnally, J. C., \& Bernstein, I. H. (1994). Psychometric theory (3rd ed.). New York: McGraw-Hill.

Okebukola, P. A., \& Jegede, O. J. (1989). Determinants of occupational stress among teachers in Nigeria. Educational Studies, 15, 23-26.

Olaitan, O. L., Oyerinde, O. O., Obiyemi, O., \& Kayode, O. O. (2010). Prevalence of job stress among primary school teachers in South West, Nigeria. African Journal of Microbiology Research, 4, 339-342.

Olivier, M., \& Venter, D. (2003). The extent and causes of stress in teachers in the George region. South African Journal of Education, 23(3), 186-192.

Paulse, J. (2005). Sources of occupational stress for educators, with specific reference to the inclusive education model in the Western Cape. (Diss. Masters Thesis.), University of Western Cape, Western Cape, Western Cape, South Africa.

Sheikh, T. L., Mohammed, A., Agunbiade, S., Ike, J., Ebiti, W. N., \& Adekeye, O. (2014). Psycho-trauma, psychosocial adjustment, and symptomatic post-traumatic stress disorder among internally displaced persons in Kaduna, Northwestern Nigeria. Frontiers in Psychiatry, 5, 127. doi:10.3389/fpsyt.2014.00127.

Tsai, E., Fung, L., \& Chow, L. (2006). Sources and manifestations of stress in female kindergarten teachers. International Education Journal, 7(3), 364-370.

\section{Submit your manuscript to a SpringerOpen ${ }^{\circ}$ journal and benefit from:}

- Convenient online submission

Rigorous peer review

- Immediate publication on acceptance

- Open access: articles freely available online

- High visibility within the field

- Retaining the copyright to your article

Submit your next manuscript at $\gg$ springeropen.com 